\title{
Investigation on the Performance of Diesel Engine Using Various Bio Fuels and the Effect of Temperature Variation
}

\author{
Murugu Mohan Kumar Kandasamy \& Mohanraj Thangavelu \\ School of Mechanical Engineering, SASTRA University \\ Thanjavur 613402, Tamilnadu, India \\ E-mail:kmohan2001@rediffmail.com \\ Rajamohan Ganesan \\ School of Engineering and Science, Curtin University Technology \\ Sarawak Campus 98009, Miri, Malaysia
}

\begin{abstract}
This paper discusses the performance characteristics of a single cylinder diesel engine using rice bran and pungam oil blended with diesel fuel. The experiments were carried out for the various blends i.e., B20, B40, B60, B80 and the results were compared with the neat diesel. The blended fuel is preheated before it is being injected to cylinder. The preheating ensures the enhancement of combustion efficiency and the over all performance of the engine.
\end{abstract}

Keywords: Diesel engine, Vegetable oils, Performance Characteristics, Blending, Heating temperatures

\section{Introduction}

Ever since the world witnessed the oil crisis, there has been unprecedented stockpiling of oil taking place by the developed countries. Production of world's estimated oil reserves is expected to be peak between 2010 and 2030. Especially the demand of diesel fuel has grown from 39.81 million metric tons in 2001-2002 to 52.32 million metric tons in 2007-2008. Therefore it is important to explore the feasibility of substitution of diesel with an alternative fuel, which can be produced with in the country on a massive scale for commercial utilization.

Vegetable oils are considered as good alternatives to diesel as their properties are close to diesel. Thus, they offer the advantage to be used in existing diesel engine without any engine modifications. They have a reasonably high cetane number. The flash point of vegetable oils is high and hence it is safe to use them. Vegetable oils typically have large molecules, with carbon, hydrogen and oxygen being present. They have a structure similar to diesel fuel, but differ in the type of linkage of the chains and have a higher molecular mass and viscosity. The presence of oxygen in vegetable oils raises the stoichiometric fuel air ratio. Contrary to fossil fuels, vegetable oils are free from sulfur and heavy metals. The heating value is slightly lower than diesel. It has been reported that the methyl and ethyl esters of vegetable oil can result in superior performance than neat vegetable oils.

Larry Wagner et al., (1984) studied the effect of soybean oil esters on performance and emissions of a four-cylinder direct injection turbocharged diesel engine. They found that the engine performance with soybean oil esters did not differ to a great extent from that of diesel fuel performance. Clark et al., (1984) studied the effect of methyl and ethyl esters of soybean oil on engine performance and durability in a direct injection four-cylinder diesel engine. They observed that the engine fuelled with soybean esters resulted in a slightly less power combined with an increase in fuel consumption. Emissions were found to be similar to diesel. Nobukazu Takagi and Koichiro Itow (1984) conducted experiments on a single cylinder direct injection diesel engine with rapeseed oil and palm oil as fuels. Ramesh et al.(1989) investigated the performance of a glow plug assisted hot surface ignition engine using methyl ester of rice bran oil as fuel. Normal and nimonic crown pistons were used for their tests. They reported improvement in brake thermal efficiency about $1 \%$ when the glow plug is on. The percentage improvement in brake thermal efficiency was more in the case of normal piston compared to nimonic piston. Brake thermal efficiency was higher with nimonic piston at low power outputs than normal piston. They observed reduced ignition delay in both cases with glow plug assistance. No significant changes in hydrocarbon and carbon monoxide emissions with methyl ester of rice bran oil using glow plug ignition were noted. Perkins and Peterson (1991) conducted a 1000-hour durability test on a compression ignition engine when fueled with methyl ester of winter rapeseed oil. Based upon the evaluation of engine performance, wear and injector deposits as indication of engine durability, they noted that the methyl ester of winter rape oil appeared to be equal to diesel fuel. They also reported that the major disadvantage for the methyl ester of winter rape oil was its cloud 
and pour points, which eliminate its use in cold weather. Kyle Scholl and Spencer Sorenson (1993) investigated the combustion characteristics of soybean oil methyl ester in a four cylinder naturally aspirated direct injection diesel engine and compared the results with the conventional diesel fuel. Masjuki and Abdulmuin (1996 a), (1996 b) conducted experiments on a water-cooled direct injection, ISUZU, four-cylinder, four-stroke engine. They reported that palm oil derived fuels result in performance comparable to diesel with improved combustion stability of the engine. They observed that the emission characteristics were good except that CO levels. Ken Friis Hansen and Michel Grouleff Jensen (1997) conducted several studies on a six-cylinder direct injection horizontal turbocharged diesel engine. They used methyl ester of rapeseed oil for their experiments. They found that there was a decrease in hydrocarbon and carbon monoxide emissions but an increase in NOX and particulate emission. Varaprasad et al. (1997) studied the effect of using Jatropha oil and esterified Jatropha oil on a single cylinder diesel engine. They found that the brake thermal efficiency was higher with esterified Jatropha oil as compared to raw Jatropha oil but inferior to diesel and also reported low NOX emissions and high smoke levels with neat Jatropha oil as compared to etserified Jatropha oil and diesel. Shaheed and Swain (1999) conducted the experiments on a single cylinder air cooled naturally aspirated direct injection diesel engine using coconut oil and methyl ester of coconut oil and diesel. They reported that the engine performed well on the three fuels except for the initial engine starting problems with coconut oil. Swain and Shaheed (2000) also conducted experiments on a single cylinder direct injection Lister Petter diesel engine with the same oil. They observed that the esters derived from coconut oil have many characteristics similar to diesel fuel with little performance and emission differences. They concluded that the fuel derived from the coconut oil is a potential alternative for operating a standard diesel engine without any engine modifications. Abdul Moneyem and Van Gerpen (2001) conducted experiments to characterize the effect of oxidized Bio diesel on engine performance and emissions. They used methyl soyate (Bio diesel) for testing a turbocharged direct injection diesel engine. They found that the performance of neat Bio diesel and it's blend with diesel were similar to neat diesel fuel operation. They also found a significant reduction in Bosch smoke number with neat Bio diesel and its blend when compared with diesel.

Recep Altin et al. (2001) conducted experiments on a single cylinder direct injection diesel engine to evaluate the performance and exhaust emissions using refined sunflower oil, cottonseed oil, soybean oil and their methyl esters. They found little power loss, higher particulate emissions and less $\mathrm{NO}_{\mathrm{X}}$ emissions with neat vegetable oils. Kaligeros et al. (2003) conducted experiments on a single cylinder indirect injection Petter diesel engine using olive oil and sunflower oil as fuels in different proportions with marine diesel. They reported lower unburned hydrocarbon, carbon monoxide, particulate and nitrogen oxide emissions with blends than neat vegetable oils.

\section{Engine Details}

$\begin{array}{lll}\text { Make } & : & \text { COMET } \\ \text { No. of Cylinder } & : & \text { one } \\ \text { Orientation } & : & \text { vertical } \\ \text { Cycle } & : & 4 \text { Strokes } \\ \text { Ignition System } & : & \text { compression Ignition } \\ \text { Bore and stroke } & : & 80 \mathrm{~mm} \times 110 \mathrm{~mm} \\ \text { Displacement volume } & : & 553 \mathrm{cc} \\ \text { Compression ratio } & : & 18: 1 \\ \text { Arrangement of valves } & : & \text { overhead } \\ \text { Combustion Chamber } & : & \text { hemi spherical open Chamber (Direct Injection) } \\ \text { Rated power } & : & 3.5 \mathrm{~kW} @ 1500 \mathrm{rpm} \\ \text { Cooling Medium } & : & \text { water cooled }\end{array}$

Fuel tank with heater, temperature regulator and stirrer unit are the accessories used in the experimental set up for blending and heating the oil. The oil is blended with diesel in different proportions. The temperature is varied from $27^{\circ} \mathrm{C}$ to $80^{\circ} \mathrm{C}$. The blended oil is stirred continuously for better mixing. Continuous heating is required in order to reduce the viscosity of the blended oil so that the engine performance will improve.

\section{Experimental Investigation}

The engine was run with the various blends (B20, B40, B60 and B80) and with pure diesel by varying the temperatures from $27^{\circ} \mathrm{C}$ to $80^{\circ} \mathrm{C}$ at different loads and with rated speed of $1500 \mathrm{rpm}$. The observations were made on Brake power, Fuel consumption and Exhaust gas temperature for the various loads and the performance parameters like Brake power, Brake thermal efficiency, Total fuel consumption and Specific fuel consumption have been calculated for all the blends and the performance graph have been drawn. 


\section{Results and Discussion}

\subsection{Rice Bran Oil}

\subsubsection{Break Power Vs Specific Fuel Consumption}

The following figures 1 to 4 show the Break Power (B.P) versus Specific Fuel Consumption (S.F.C) using Rice Bran Oil at different temperatures.

\subsubsection{Break Power Vs Specific Break Thermal Efficiency}

The following figures 5 to 8 show the Break Power (B.P) versus Break Thermal Efficiency (B.T.E) using Rice Bran Oil at different temperatures.

\subsection{Pungam Oil}

\subsubsection{Break Power versus Specific Fuel Consumption}

The following figures 9 to 12 show the Break Power (B.P) versus Specific Fuel Consumption (S.F.C) using Pungam Oil at different temperatures.

\subsubsection{Break Power versus Break Thermal Efficiency}

The following figures 13 to 16 show the Break Power (B.P) versus Break Thermal Efficiency (B.T.E) using Pungam Oil at different temperatures.

\section{Conclusions}

It is concluded from the above graph that the highest engine efficiency is obtained for the B60 of pungam oil and also it is evident that the efficiency increases with increase in the temperature. Where as for the rice bran oil, the variation in the engine efficiency is very minimum with change in temperature and the performance of the engine is found to be good for the B40 blend. However the over all performance of the engine is found to be good when the oil and diesel blend is supplied to the cylinder after pre heating.

\section{References}

Abdul Monyem., Jon, H and Van Gerpen. (2001). 'The effect of Biodiesel oxidation on Engine Performance and Emissions', International Journal of Biomass and Bio Energy, No.20, pp. 317-325.

Amin-Nejad S., Smith J.S., and Lucas.J. (2003). "A Visual Servoing System for Edge Trimming of Fabric Embroideries by Laser." Journal of Mechatronics, Pergamon Press, New York. ISSN 0957-4158. 13(6): pp533-551.

Clark, S.J., Wagner, L., Schorck, M.D. and Piennaar, P.G. (1984). 'Methyl and Ethyl Soybean Esters as Renewable Fuels for Diesel Engines', Journal of American Oil Chemist Society, Vol. 61, No.10, pp.1632-1638.

Kaligeros, S., Zannikos, F., Stournas, S., Lois, E., Anastopoulosd, G., Teas Ch and Sakellaropoulos, F. (2003). 'An Investigation of Using Bio diesel/Marine Diesel blends on the Performance of a Stationary Diesel Engine', Journal of Biomass and Bio energy, No.24, pp. 141-149.

Ken Friis Hansen and Michael Grouleff Jensen. (1997). 'Chemical and Biological Characteristics of Exhaust Emissions from a DI Diesel Engine Fuelled with Rapeseed Oil Methyl Ester (RME)', Society of Automotive Engineers, Paper No. 971689. 17.

Larry E. Wagner., Stanley J. Clark and Mark D. Schrock. (1984). 'Effect of Soybean Oil Esters on the Performance, Lubrication Oil and Water of Diesel Engines', Society of Automotive engineers, Paper No. 841385.

Masjuki, H., Abdulmuin, M.Z. and Sii, H.S. (1996 a). 'Indirect Injection Diesel Engine Operation on Palm Oil Methyl Esters and Its Emulsions’, Proceedings of Institute of Mechanical Engineers, No. 211, pp.291 - 299.

Masjuki, H., Abdulmuin M.Z and Sii, H.S. (1996 b). 'Investigation on Preheated Palm Oil Methyl Esters in Diesel Engine', Proceedings of Institute of Mechanical Engineers, No.210, pp.131 - 138.

Nobukazu Takagi, and Koichiro Itow. (1984). 'Low Carbon Flower Buildup Low Smoke and Efficient Diesel Operation with Vegetable Oils by Conversion to Monoesters and Blending with Diesel Oil or alcohols', Society of automotive engineers, Paper No.841161.

Ramesh, A., Nagalingam, B. and Goparakrishnan, K.V. (1989). 'Performance of Glow Plug Surface Ignition Engine with Methyl ester of Rice Bran Oil as Fuel', Proceedings of XI National Conference on I.C. Engines and Combustion, Indian Institute of Technology Madras, Tamil Nadu state, India.

Recep Altin., Selim Cetinkaya and Huseyin Serdas Yucesu. (2001). 'The Potential of Using Vegetable oil Fuels as Fuel for Diesel Engines', International Journal of Energy Conversion management, No.42, pp.529 - 538.

Shaheed, A and Swain, E. (1999). 'Combustion Analysis of Coconut Oil and Its Methyl Esters in a Diesel Engine', Proceedings of Institute of Mechanical Engineers, Vol 213, Part A, pp. 417-425. 
Swain, E and Shaheed, A. (2000). 'An Experimental Study to Evaluate the Use of Coconut Based Fuels as Alternatives to Diesel Oil', Journal of the Institute of Energy, No.73, pp. 100-105.

Varaprasad, C.M., Muralikrishna, M.V.S and Prabhakar reddy, C. (1997). 'Investigations on Bio diesel (Esterified Jatropha Curcus Oil) in Diesel Engines' XV National Conference on I.C. Engines and Combustion, Anna University, Chennai, Tamil Nadu, India.

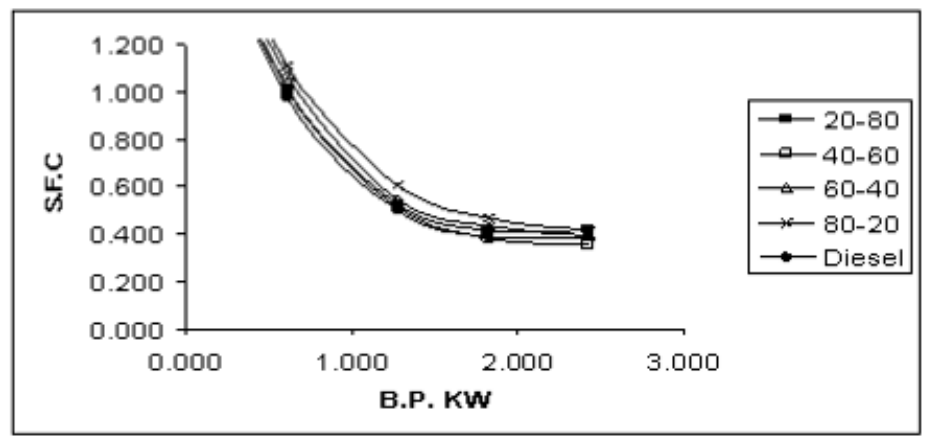

Figure 1. B.P Vs S.F.C at $27^{\mathrm{O}} \mathrm{C}$

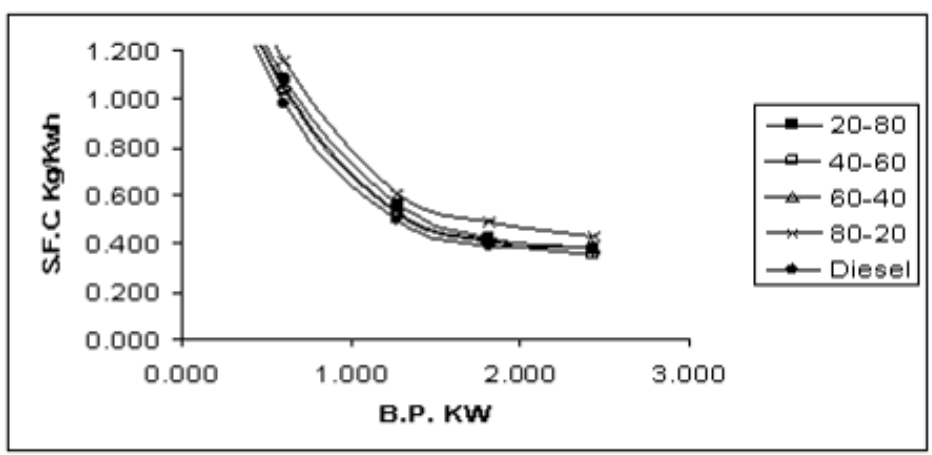

Figure 2. B.P Vs S.F.C at $40^{\circ} \mathrm{C}$

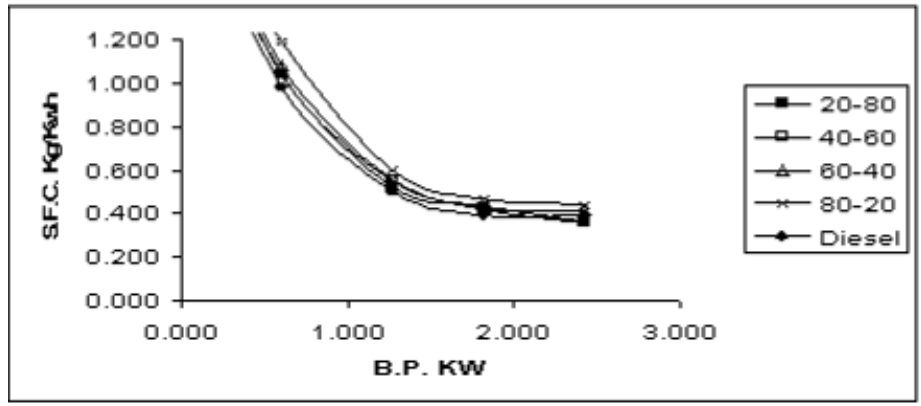

Figure 3. B.P Vs S.F.C at $60^{\circ} \mathrm{C}$

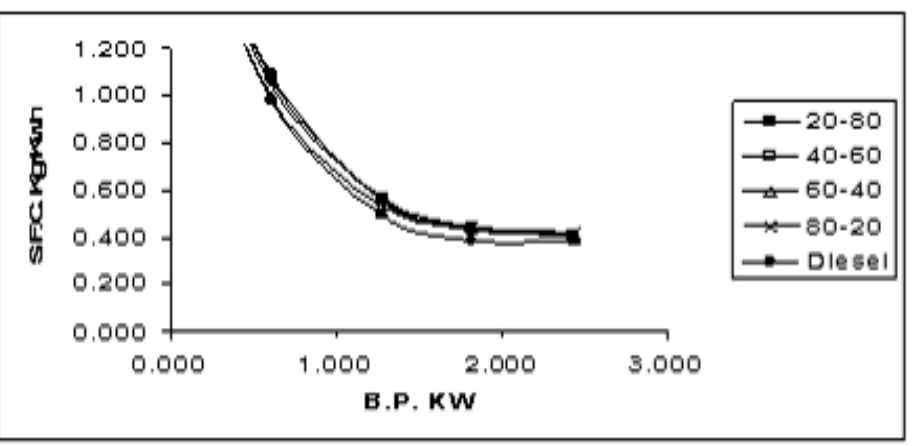

Figure 4. B.P Vs S.F.C at $80^{\circ} \mathrm{C}$ 


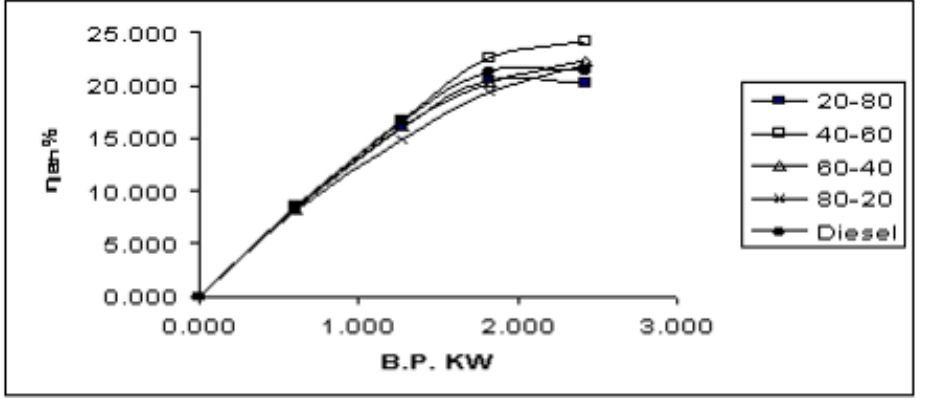

Figure 5. B.P Vs B.T.E at $27^{\circ} \mathrm{C}$

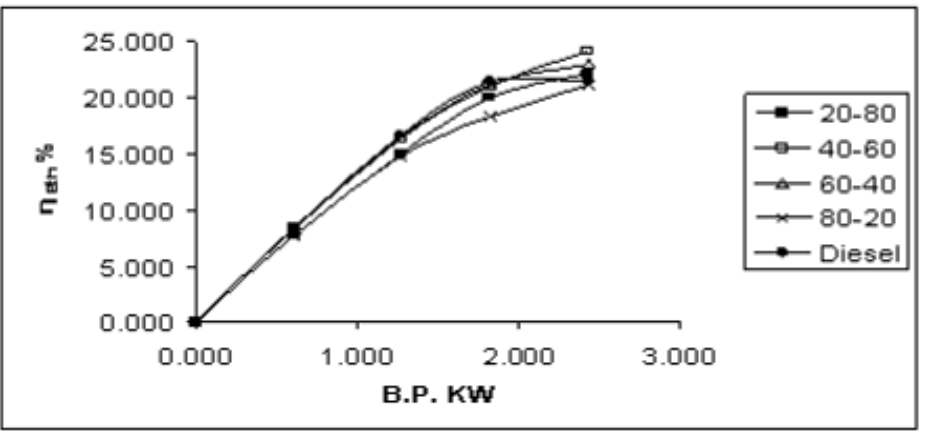

Figure 6. B.P Vs B.T.E at $40^{\circ} \mathrm{C}$

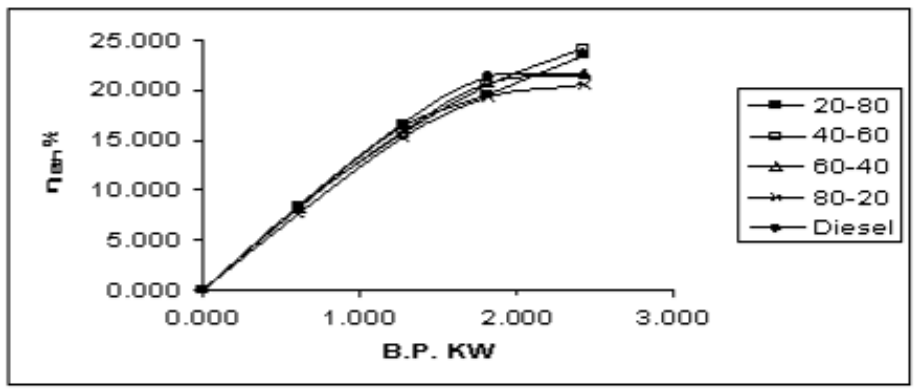

Figure 7. B.P Vs B.T.E at $60^{\circ} \mathrm{C}$

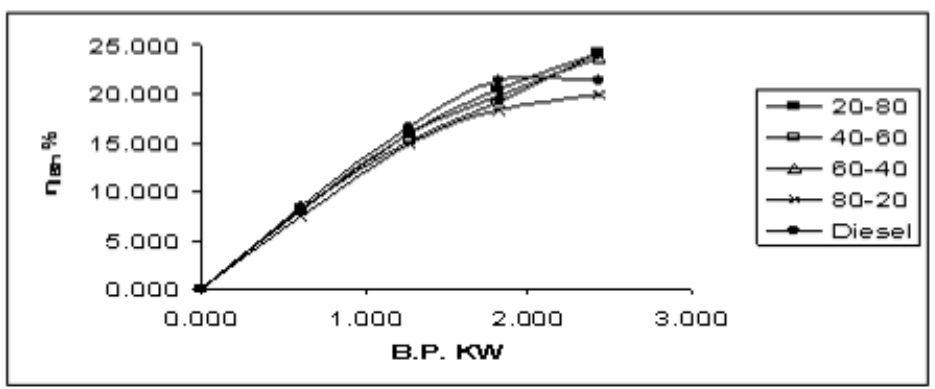

Figure 8. B.P Vs B.T.E at $80^{\circ} \mathrm{C}$ 


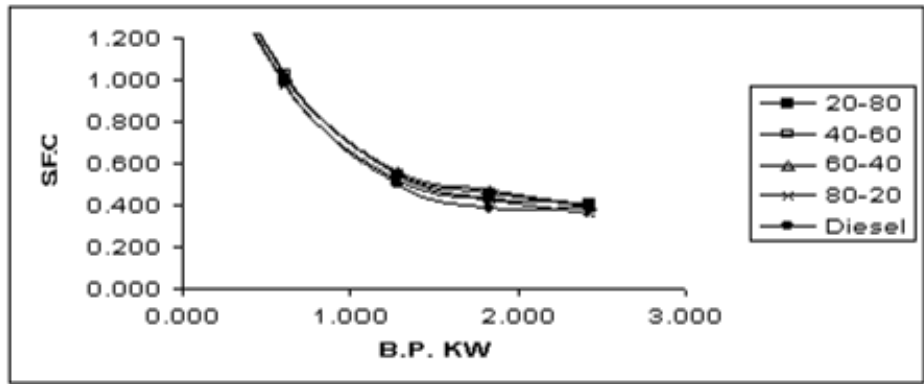

Figure 9. B.P Vs S.F.C at $27^{\circ} \mathrm{C}$

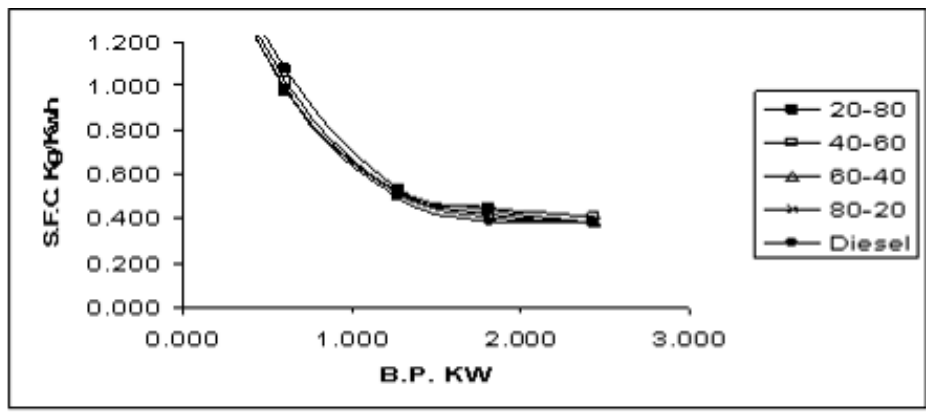

Figure 10. B.P Vs S.F.C at $40^{\circ} \mathrm{C}$

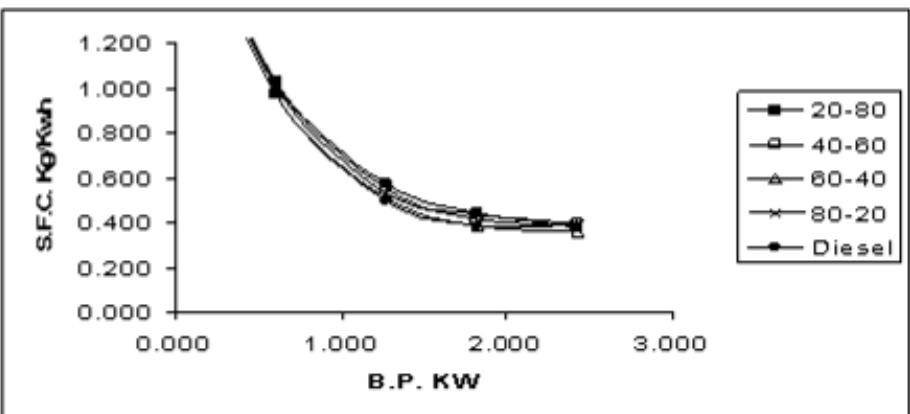

Figure 11. B.P Vs S.F.C at $60^{\circ} \mathrm{C}$

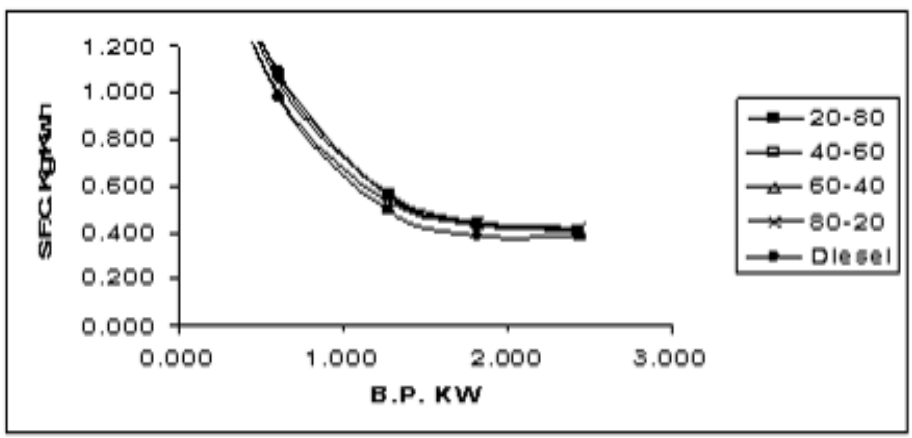

Figure 12. B.P Vs S.F.C at $80^{\circ} \mathrm{C}$ 


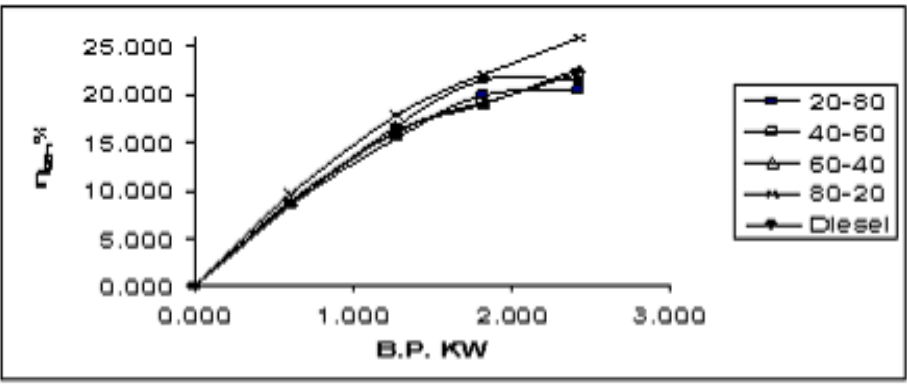

Figure 13. B.P Vs B.T.E at $20^{\circ} \mathrm{C}$

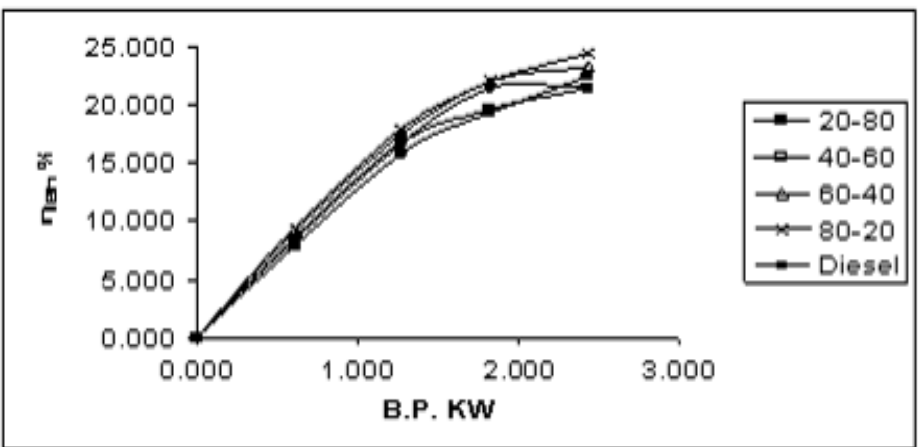

Figure 14. B.P Vs B.T.E at $40^{\circ} \mathrm{C}$

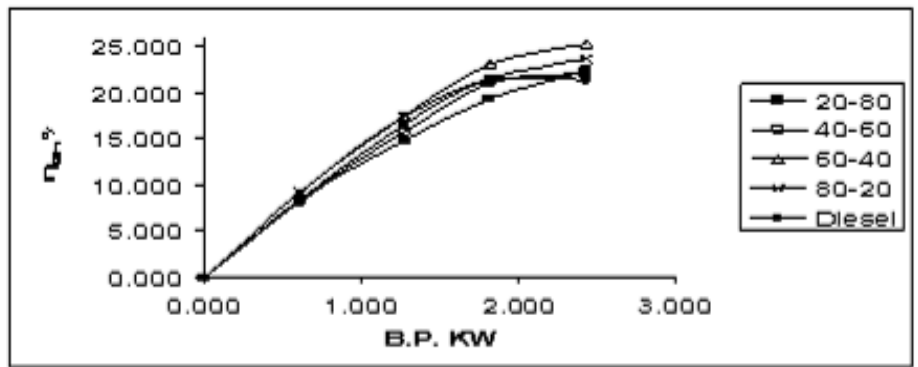

Figure 15. B.P Vs B.T.E at $60^{\circ} \mathrm{C}$

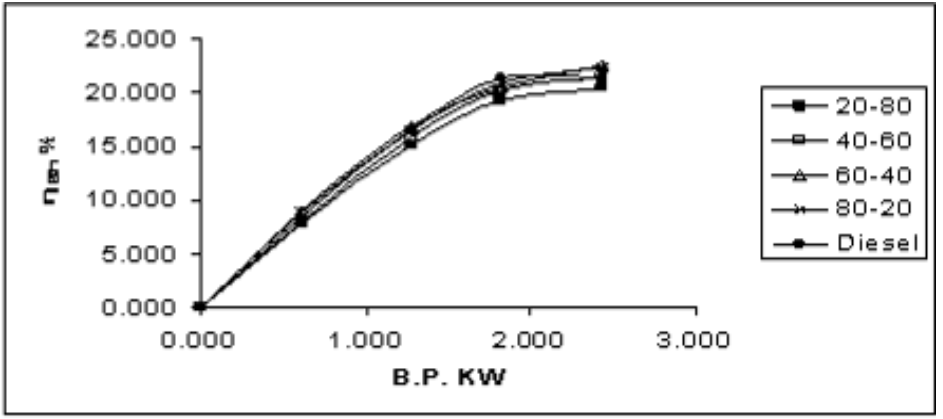

Figure 16. B.P Vs B.T.E at $80^{\circ} \mathrm{C}$ 